\title{
Should Dentist wear white coat or not? A cross-sectional study
}

\author{
Dr. Shweta Deshmukh ${ }^{1}$, Dr. Anshul Sharma ${ }^{2}$, Dr. Vikas Soni ${ }^{3}$, \\ Dr. Pallavi Thombare ${ }^{4}$, Dr. Harish Tiberewal ${ }^{5}$, Dr. Apeksha lavankar ${ }^{6}$ \\ ${ }^{1,6}$ Dept. of community dentistry, ${ }^{4}$ Dept. of orthodontics S.P.D.C., Wardha (Maharashtra) \\ ${ }^{2}$ Dept. of periodontics, Rajasthan Dental College, Jaipur (Raj) \\ ${ }^{3}$ Dept. of Orthodontics, Jaipur Dental College, Jaipur (Raj) \\ ${ }^{6}$ Dept. of Community Dentistry, v.y.w.s. dental college, Amravati (Maharashtra)
}

\begin{abstract}
Introduction: This cross-sectional study was designed to compare the views of dentist and patients on whether dentist should wear white coats or not.

Material and methods: Patients attending a dental hospital for a consultation appointment and the dentist were asked to assess their view related to their preference for white coat and behaviors of the dental care providers using a questionnaire. The surveyed population consisted of total of 200 patients and 62 dentists.

Results: The study reveals that a most of the responds felt white coat was important and that they prefer dental professionals to wear white coat. Significantly more of those aged over 60 thought their dentist should wear white coats in comparison with those under 60. Patients aged 18-30 were least likely to want their dentist to wear a white coat.

Conclusion: More patients than dentist and especially those older than 60 years, felt that doctors should wear them for easy identification. However, most of the dentist views an infection risk as a hurdle in wearing white coat.
\end{abstract}

Keywords: white coat

\section{Introduction-}

Doctors first wore white coats in the late 19th century when science began to make significant inroads into medicine and physicians adopted the laboratory coat as their own ${ }^{1}$. Its initial purpose was to protect the patient and physician from cross-contamination, but, as the partnership between science and medicine ${ }^{2}$ transformed hospitals from institutions for the dying to centers for curing the sick, the white coat became a potent symbol of the authority of science and the art of healing. Superimpose on this metamorphosis Western cultural connotations of whiteness - "life, purity, innocence, superhuman power, goodness - and it is easy to see how the white coat became the favored garment for physicians" ${ }^{1,3}$

However, as the 20th century advanced, and sociologists turned their attention to medicine $e^{4,5}$ and the dynamics of the patient-doctor relationship, the white coat was seen increasingly as a barrier to an effective communication. In an attempt to dispel this perception, pediatricians, psychiatrists and doctors in private practice shed the white coat. Furthermore, the changes in society and healthcare that turned doctors into "healthcare providers" and patients into "clients, consumers or customers" also witnessed the extinction of the white-coated doctor. Today, doctors in our hospitals have become a hidden species, virtually indistinguishable from other hospital personnel or even patients' visitors.

These findings are not surprising. There is now substantive information that adult patients prefer doctors in clinics and hospitals to be traditionally, or at least smartly, dressed ${ }^{6,11}$ to wear a necktie ${ }^{6,8,10,11}$ to have short hair ${ }^{7,9,11}$ and to wear white coats with a name tag. ${ }^{6,7,911}$ Does all this foreshadow a rebirth of doctors in white coats? Probably not. Most of the current information on patients' preferences for doctors' attire is derived from limited cross-sectional surveys. In the current era of evidence-based healthcare, any return of the white coat awaits the outcome of a randomized controlled trial to settle the question: to be or not to be in a white coat.

We therefore embarked upon a study in a large cohort of patients to clarify the viewpoints of outpatients and dentist.

\section{Material and methods-}

The study was undertaken at S.P. dental college and Hospital, Wardha located in the Maharashtra State, India and used a randomized cross-sectional design, which made use of survey methodology and was conducted during the third week of February 2006. Consent was obtained from all participating patients and doctors and approval for the study was obtained from the hospital ethics committee of S.P. Dental College and Hospital, Wardha. 
Patients who were 18 years of age or older were allowed to participate. Exclusion criterion includes patients if they were illiterate, had a suboptimal mini-mental test or for any reason which would hinder their perceptive of the questionnaire. The questionnaire dispensed by a non-clinical member of staff were completed in the waiting hall prior to the participant's appointments with receptionist help to most of the patients as questionnaire were not in local language and later were placed in a sealed box by the respondents before they left the faculty.

A total of 425 questionnaires were distributed over a 6 week period of which 10 get damage and 15 were excluded due to incomplete information and non response on the participation site . So a final survey of 400 questionnaires was distributed among the patients attending a dental hospital. With regards to dentist 63 questionnaire were distributed of which only 1 could not get collected with final pool of 62 questionnaires. We obtained a demographic information on patient's and dentist's age, sex and data on attitudes about white coat were rated.

Patients were asked to answer "yes" or "no" to the question "Do you think dentist should wear white coats?" but were given the opportunity to qualify their answers by agreeing or disagreeing to suggestions (from list A, table 1). Patients were also asked if their dentist wore a white coat. Dentist were asked "Do you think dentist should wear white coats?', They were allowed to qualify their answers by agreeing or disagreeing with suggestions (table 1).

\section{Statistical analysis-}

Completed patients questionnaires were collected and passed blind to independent statisticians where they were analyzed for response frequency and the results tabulated. The statistical package for social sciences (SPSS) was used for data analysis (Apache, version 2.0) using the chi-square test and multifactorial analysis. Statistical significance was determined at $P<0.05$.

\section{Results-}

Results are tabulated from 1-4.The mean age of patients was 45 (range 18-70); the mean age of doctors was 31 (range 24- 50)

Table 1 shows that out of the total 200 patients and 62 dentist, there were more of the female patients $(58 \%)$ than that of the dentist $(42 \%)$

Table1. Sample distribution

\begin{tabular}{|l|cl|cl|}
\hline Sex & Patient & (\%) & Dentist & (\%) \\
\hline Male & 84 & $(42)$ & 31 & $(50)$ \\
\hline Female & 116 & $(58)$ & 31 & $(50)$ \\
\hline Total & 200 & $(100)$ & 62 & $(100)$ \\
\hline
\end{tabular}

Table 2 shows $67 \%$ said that their dentists should wear white coats. Variation of patients' views according to age is shown in table 2 . Significantly more of those aged over 60 thought their dentist should wear white coats in comparison with those under 60. Patients aged 18-30 were least likely to want their dentist to wear a white coat. A highly statistically significant difference in views of different age of patients was seen between those who said their dentist wore a white coat and those who said their dentist did not.

Table2. Should Dentist wear white coat? Views according to patient's age

Chi-square $=26.39$

\begin{tabular}{|l|ll|cc|}
\hline Patient Age & Yes & $\mathbf{( \% )}$ & No & $\mathbf{( \% )}$ \\
\hline $\mathbf{1 8 - 3 0}$ & 20 & $(10)$ & 16 & $(8)$ \\
\hline $\mathbf{3 1 - 4 0}$ & 22 & $(11)$ & 24 & $(11)$ \\
\hline $\mathbf{4 1 - 5 0}$ & 22 & $(11)$ & 8 & $(4)$ \\
\hline $\mathbf{5 1 - 6 0}$ & 30 & $(15)$ & 8 & $(4)$ \\
\hline $\mathbf{6 0}$ above & 40 & $(20)$ & 12 & $(6)$ \\
\hline Total & 134 & $(67)$ & 66 & $(33)$ \\
\hline
\end{tabular}

df $=4 P$ $=0.000$

Table 3 illustrates that of the total 200 patients, 134 who said dentist should wear white coats; ease of identification $(n=84)$ was the foremost choice of the patients with maximum $(22 \%)$ in the older age group (60 above). In addition, following reasons were also given: looks more professional $(\mathrm{n}=24)$, prevents infection $(n=18)$ and last was the tradition with only $6 \%$. Reason for patient view was found to be statistically significant. 
Table 3. Why Dentist should wear white coat? Views according to patient's age

\begin{tabular}{|c|c|c|c|c|}
\hline Patient age & $\begin{array}{c}\text { Tradition } \\
(\%)\end{array}$ & $\begin{array}{l}\text { Identification } \\
\text { Ease }(\%)\end{array}$ & $\begin{array}{l}\text { Infection } \\
\text { Control (\%) }\end{array}$ & $\begin{array}{l}\text { Professional } \\
\text { Look }(\%)\end{array}$ \\
\hline 18- 30 & $\begin{array}{ll}2 & (1.5)\end{array}$ & $\begin{array}{ll}10 & (7.5)\end{array}$ & $\begin{array}{ll}4 & (3.0)\end{array}$ & $4 \quad(3.0)$ \\
\hline $31-40$ & 0 & $14 \quad(10.4)$ & $4 \quad(3.0)$ & $4 \quad(3.0)$ \\
\hline $41-50$ & 0 & $12 \quad(9.0)$ & $6 \quad(4.5)$ & $4 \quad(3.0)$ \\
\hline $51-60$ & $4 \quad(3.0)$ & (13.4) & $2 \quad(1.5)$ & $6 \quad(4.5)$ \\
\hline Total & $8 \quad(6.0)$ & $(62.7)$ & 18 (13.4) & $24(17.9)$ \\
\hline
\end{tabular}

Chi-square $=30.62 \mathbf{d f}=12 \quad \boldsymbol{P}=0.002$

Table 4 depicts that ease of identification was the common choice among male and female patients. However, it was interesting to note that no male patient view on the infection control protocol, whereas least view among the female was tradition (1.5\%) listed tradition.

Table 4.Why dentist should wear white coat? Views according to patient's sex

Chi-

\begin{tabular}{|c|c|c|c|c|}
\hline Patient Sex & $\begin{array}{c}\text { Tradition } \\
(\%)\end{array}$ & $\begin{array}{l}\text { Identification } \\
\text { Ease (\%) }\end{array}$ & $\begin{array}{l}\text { Infection } \\
\text { Control (\%) }\end{array}$ & $\begin{array}{l}\text { Professional } \\
\text { Look (\%) }\end{array}$ \\
\hline Male & $6 \quad(4.5)$ & $44 \quad(32.8)$ & 0 & $6 \quad(4.5)$ \\
\hline Female & $\begin{array}{ll}2 & (1.5)\end{array}$ & $\begin{array}{ll}40 & (29.9)\end{array}$ & $18 \quad(13.4)$ & 18 (13.4) \\
\hline Total & $\begin{array}{ll}8 & (6.0)\end{array}$ & \begin{tabular}{|ll}
84 & $(62.7)$
\end{tabular} & $\begin{array}{ll}18 & (13.4)\end{array}$ & $24(17.9)$ \\
\hline
\end{tabular}

square $=46.4 \mathbf{d f}=3 \boldsymbol{P}=0.000$

Table 5 shows that almost $51 \%$ of the dentist in a hospital agreed that dentist should wear white coat compare to $67 \%$ of the patients. Of which dentist in the age group of $31-40(22.6 \%)$ were more likely to think that doctors should wear white coats.

Table5. Should Dentist wear white coat? Views according to Dentist's age

\begin{tabular}{|c|c|c|}
\hline Dentist's Age & Yes $(\%)$ & No $(\%)$ \\
\hline $18-30$ & $10 \quad(16.1)$ & $20 \quad(32.3)$ \\
\hline $31-40$ & $(22.6)$ & $(12.9)$ \\
\hline $41-50$ & $(12.9)$ & $(3.2)$ \\
\hline Total & $32 \quad(51.6)$ & (48.4) \\
\hline
\end{tabular}

Chi-square $=17.02 \quad \mathbf{d f}=2 \quad P=0.000$

\section{Discussion}

Our study showed that $67 \%$ of patients $(n=200)$ favored dentist wearing white coats. These findings when relate to medical specialties we establish that Harnett ${ }^{14}$ Tiwari et $\mathrm{al}^{15}$, and Dunn et $\mathrm{al}^{6}$ had found that $59 \%$ of oncology patients $(n=180), 62 \%$ of inpatients at Harlow hospital $(n=160)$, and $65 \%$ of inpatients $(n=200)$ respectively, favoured white coats.

This differs from the more recent findings of Dover ${ }^{12}$ and Gooden et $\mathrm{al}^{3}$ who found that $48 \%$ of patients $(n=300)$ and $36 \%$ of inpatients $(n=154)$ respectively, favoured white coats. The variation in these results reflects the differing opinions of patients in different countries and time periods.

In our study, we found that ease of identification $(n=84)$ was the foremost choice of the patients with maximum $(22 \%)$ in the older age group (60 above). Of the reasons given by patients for doctors to wear white coats the most common reasons in our study, as in Harnett's, ${ }^{14}$ were for easy identification especially in the age group above 60 and because white coats made doctors look more professional suggesting the move towards the white coat by dentist in the hospital is justified.

Although medical opinion in different parts of the world is changing away from the white coat, others feel they still have a positive role. In the USA robbing ceremonies are common ${ }^{3}$, and Van Der Weyden from Australia suggests the time might be right to rediscover the white coat as a symbol of our purpose and pride as a profession $^{8}$. This discrepancy is of concern because it suggests other groups who wear white coats (phlebotomists, porters, and electricians) may be mistaken for doctors. In a hospital where other health care workers wear white coats, it was also take into considerations that in addition, a stethoscope and name badge would be a better form of identification.

Patients (especially those over 60) have significantly different views on whether dentist should wear white coats. Patients want to be able to identify their dentist and see the white coat as a means of achieving this. Further studies are needed to assess whether this affects patients' perceived quality of care or not. In our study, we found that $51 \%$ of the dentist sampled said they thought white coats transmit hospital acquired infections. In 
contrast less than $1 \%$ of patients expressed the view that white coats could be a health hazard, while $6.5 \%$ said they help prevent infections. These differences may be related to awareness about the risk factors for transmitting hospital acquired infections.

We were unable to find studies that demonstrated that wearing white coats increased the risk of hospital acquired infection. However, several studies have documented bacterial contamination of both white coats and nurses' uniforms, suggesting a potential risk. One survey of 100 doctors at the East Birmingham Hospital isolated Staphylococcus aureus from $25 \%$ of coats ${ }^{21}$. Further studies are required to determine if suits, shirts, or ties worn by doctors are similarly colonized and to examine if not wearing white coats reduces hospital acquired infections.

The fact that maximum number of patients over 60 year olds in our sample would like their dentist to wear white coats is a strong argument for these patients either to be educated about the disadvantages of dentists wearing white coats, or for dentists to change their behaviour and wear them. In view of the evidence showing white coats as a potential source of infection we would like to favor the former policy.

The paucity of older dentist means that the mean age of the dentists is much lower than that of the patients. However it is the younger dentists who are more visible on a daily basis to patients. Thus, the behaviour of younger dentist is more relevant to patients and this study.

In our study, we found that nearly $51 \%$ of the dentist thought that dentist should wear white coat. Whereas, when comparing our results to medical specialists of psychiatrists and pediatrics said that they did not wear white coats because their patients found them threatening and hence they interfered in the doctor-patient relationship. The views of pediatricians may reflect the findings of a study by Barrett and Booth who found children regard formally dressed doctors as competent but not friendly, and those casually dressed as friendly but not competent. ${ }^{13}$

Dentists and patients (especially those over 60) have significantly different views on whether dentist should wear white coats. Patients want to be able to identify their dentists and see the white coat as a means of achieving this. It can be suggested that further studies are need to assess whether this affects patients' perceived quality of care, and whether patient education about infection risk, and the fact that dentist also wear white coats, will alter their view.

\section{Conclusion-}

Most of the patients than dentist and especially those older than 60 years, feel that dentist should wear white coat for easy identification. However, most of the dentist views an infection risk as a hurdle in wearing white coat.

\section{References}

[1]. Blumhagen DW. The doctor's white coat. The image of the physician in modern America. Ann Intern Med1979;91:95-119.

[2]. Weatheral D. Science and the quiet art. Medical research and patient care. Oxford: Oxford University PRESS. 1995:55-88.

[3]. Wear D. On white coats and professional development: the formal and the Hidden curricula. Ann Intern Med 1998; 129:734-7.

[4]. Annandale E. The sociology of health and medicine. A critical introduction. Cambridge: Polity Press, 1998: 4-32.

[5]. Freidson E. Profession of medicine. New York: Harper and Rowe, 1970.

[6]. Dunn JJ, Lee TH, Percelay JM et al. Patient \& house officer attitudes on physician attire and etiquette. JADA 1987; 257:65-8.

[7]. Gjerdingen DW, Simpson DE, Titus SL. Patients' and physicians' attitudes regarding the physician's professional appearance. Arch Intern Med 1987; 147: 1209-1212.

[8]. McKinstry B, Wang J-X. Putting on the style: what patients think of the way their doctor dresses. Br J Gen Pract 1991; 41: $275-278$.

[9]. Hennessy N, Harrison DA, Aitkenhead AR. The effect of the anaesthetist's attire on patient attitudes. Anaesthesia 1993; 48: 219222 .

[10]. Gledhill JA, Warner JP, King M. Psychiatrists and their patients: views on forms of dress and address. Br J Psychiatry 1997; 171 : 228-232.

[11]. Menahem S, Shvartzman P. Is our appearance important to our patients? Fam Pract 1998; 15: $391-397$.

[12]. Dover S. Glasgow patients' attitude to doctors' dress and appearance. Health Bull (Edinb), 1991; 49:293-6.

[13]. Gooden BR, Smith MS, Tattersall JN, et al. Hospitalised patients' views on doctors and white coats. Med J Aust 2001;175:219-21.

[14]. Harnett PR. Should doctors wear white coats? Med J Aust 2001;174:343-4.

[15]. Tiwari A, Abeysinghe N, Hall A, et al. Should doctors wear white coats? The patients' perspective. J Eval Clin Pract 2001; 7:3435 .

[16]. Farraj R, Baron JH. Why do hospital doctors wear white coats? J R Soc Med 1991; 84:43.

[17]. Van Der Weyden MB. White coats and the medical profession. Med J Aust 2001; 174:324-5.

[18]. Babb JR, Davies JG, Ayliffe GA. Contamination of protective clothing and nurses' uniforms in an isolation ward. J Hosp Infect 1983; 4:149-57.

[19]. Grys E, Pawlaczyk M. Does a physician's apron protect against nosocomial infection? Ginekol Pol 1996; 67:309-12.

[20]. Loh W, Ng W, Holton J. Bacterial flora on the white coats of medical students. J Hosp Infect 2000; 45:65-8.

[21]. Wong D, Nye K, Hollis P. Microbial flora on doctors' white coats. BMJ 1991; 303:1602-4. 